\title{
From CRITICAL THINKING To REFLECTION TO CITIZEN ENGINEERS
}

\author{
E. Anne Johnson \\ Robert M. Buchan Department of Mining, Queen’s University \\ anne.johnson@queensu.ca
}

\begin{abstract}
What does it mean to be a "responsible engineer"? The question has been asked throughout history, including during times that were fraught with challenge, but the problems awaiting engineering students in Canada in 2021 are arguably unprecedented in their complexity. Technologically difficult problems resulted in recent advances such as the World Wide Web and 5G mobile communications, but today's challenge derives not only from the global scale of man-made environmental problems and their impacts, but from lack of agreement around appropriate mitigation strategies and on the need to act at all. The engineering students of today must develop solutions to problems that have newly acknowledged and highly contentious human factors. In the Canadian context, new policy is emerging from Canada's recognition that it must reconcile the harms of past policies towards Indigenous peoples. This recognition has created a discourse around equity that will shape the landscape in which graduates will practice. In preparing young engineers to navigate technological and social complexity, and to equip them to find personal fulfillment in an uncertain landscape, a reinvigorated emphasis on critical and relational thinking is required. In 2019 and 2020, students in a fourth-year class in Sustainability, (which includes a study of law, policy, and sustainability reporting metrics) participated in multiple group exercises that asked them to explore multiple facets of problematic or politically current issues. These learning activities sought to support a transformative learning experience in which students would come to recognize their ability to contribute as citizens to the development of responsible public policy. In these exercises they examined opposing positions and assessed the strengths, weaknesses, opportunities and risks, associated with each. That there was no RIGHT conclusion was emphasized. The only criteria for assessment was depth of exploration and logical chaining of evidence. Students learned about cultural perspectives from an Indigenous educator, and as they explored the diversity of viewpoints around the question of pipeline expansion in Canada. A final exercise asked students to reflect on the meanings of responsible policy and practice and how they would operationalize sustainability thinking.
\end{abstract}

CEEA-ACEG21; Paper 1

University of Prince Edward Island; June 21 - 23, 2021- 1 of 6 -
Keywords: engineering ethics, critical thinking, sustainability, transformative learning, reflection, engaged citizenship

\section{INTRODUCTION}

What does a student of mining or geological engineering need to learn in a course in sustainability? The answer is determined in part on how Canadian Engineering Accreditation Board (CEAB) graduate attributes are allocated by their school. Allocation decisions frame the ways in which sustainability can be defined and explored. Recognizing that the central concerns of sustainability coalesce around resource extraction, the Robert M. Buchan Department of Mining at Queen’s University determined in 2007 that Sustainability would be a focus of its research activities and a core topic within its undergraduate curriculum. A fourth-year course, MINE 422 Mining and Sustainability has been allocated academic units from among CEAB's complimentary skills: the impact of engineering on society and the environment, ethics and equity, professionalism, and communication. Development of these skills begins in second and third year, where they are explored from a technical perspective. In MINE 422, a dialogic lens is applied to topics under the sustainability umbrella.

The closely related but distinct terms critical thinking and dialogical thinking are employed in this paper. Educators in every field agree that critical thinking-the process of questioning the provenance or authority of knowledge, the legitimacy, the assumptions, and biases of an argumentis a desirable outcome of higher education. Dialogue is a familiar communication practice characterized by a backand-forth (also described as "call and response") pattern that ensures that both parties have the opportunity to be heard. Heath points out that dialogue is required for democracy [1], but it would be a mistake to think of dialogue strictly as a communication model. Dialogue practice is a particularly important method for exploration of differing viewpoints while dialogic thinking, builds beyond critical thinking to include diverse thinking and progressing towards inclusive thinking. Dialogic thinking 
confronts complexity by requiring that biases and assumptions be explored and evaluated but also ensuring that assumptions and biases do not blind us to the positions of others. Through acknowledgement of the potential for and legitimacy of competing realities, engineering students become equipped to develop more empathetic solutions to technical problems. The curriculum has been designed to provide opportunity to engage critically with contentious topics associated with mining and geological engineering. It exposes students to the ways in which cultural difference and the experience of colonization, as well as unresolved claims to land, contribute to the conflict associated with mining. It introduces students to techniques of dialogue and participation as tools to resolve conflicts and to create effective policy. Learning activities and assessment built the skills of critical analysis, promoted reflection on the role of the profession, and expanded understanding of the responsibility of the individual engineer to contribute to stewardship and equity: in other words, to accept the citizenship responsibilities that accompany education.

\section{CONCEPTUALIZING SUSTAINABILITY}

MINE 422 proposes that sustainability is a mindset: an integrative way of thinking that synthesizes emerging science, divergent worldviews and values, and evolving values of social and environmental (climate, water) justice. The global scale of man-made environmental problems and the lack of agreement not only around appropriate mitigation strategies but on the need to act, result in a complexity that demands new approaches to engineering education. There is an immediate need to develop solutions to technological problems that incorporate unprecedented and highly contentious human factors. Furthermore, evolving recognition that Canada must reconcile the ongoing harms resulting from past policies towards Indigenous peoples has created an urgent discourse around equity that shapes the landscape in which graduates will practice. In preparing young engineers to navigate this technological and social complexity, and to equip them to find personal fulfillment in a fraught landscape, a reinvigorated emphasis on critical thinking in context is empowering. Sustainability is an appropriate topic via which to guide students away from the comfort of the disciplinary expertise they have worked hard to acquire to a dialogical engagement with the discomfort of perspectives and values that are unfamiliar in order to expand their capacity for critical thought about the collisions between technical feasibility and social acceptability, against the question “Acceptable to whom?”

\subsection{A Philosophy of Education}

Within the themes prescribed by accreditation, learning outcomes reflect the teaching philosophy of educators. Susan Toohey suggests that five broad philosophical

CEEA-ACEG21; Paper 1

University of Prince Edward Island; June 21 - 23, 2021- 2 of 6 - approaches can be seen in university curricula: traditional or discipline based, performance based, cognitive, personal relevance/experiential and socially critical [3].

Often unquestioned, perhaps the product of the educator's own learning experiences, philosophies of teaching, brought into consciousness, reveal a logic to guide the development of an internally consistent curriculum aligned with the objectives of deeper learning. The answer to the question, "What does a mining student need to learn about sustainability is ultimately determined by their instructor's philosophy of teaching - as MINE 422, reflects a socially critical teaching philosophy.

\subsection{Socially Critical Teaching}

From a socially critical perspective, the overarching goal of educators is to help students develop an appreciation of the roots and impacts of societal problems and to be "motivated to alleviate them" [2], an objective that is shared with citizenship education. As with all teaching philosophies, the socially critical philosophy has a distinct view of knowledge - what counts as knowledge, how knowledge is legitimated, and of unique concern, how knowledge hierarchies serve to entrench social power structures. As engineering students approach graduation, with sufficient mastery of the engineering knowledge set and sufficient confidence in their identity as engineers [4], the challenge of critical thinking about disciplinary assumptions is a developmental step on the path to professionalism. It could be argued that the goal of socially critical teaching in the disciplines is to produce engaged and caring citizens ready to apply their technical expertise to society's problems [5].

\subsection{Getting Started: Foundational Concepts}

The development of the curriculum for MINE 422 has been guided by two conceptions of sustainability. First, sustainability, is a mindset or way of thinking: a collection of values, outlooks and skills that inform professional practice, private pursuits, and civic engagement. Second, sustainability thinking finds its practical application in the concept of sustainable development, which, having been defined roughly as "development that meets the needs of today without compromising the ability of future generations to meet their own need" [6], continues to evolve, offering different models of interactions among systems.

Sustainable development offers an expanding toolbox of methodologies, standards of practice, and approaches, but ultimately does not come with either answers or reliable instructions. To design solutions that contribute to sustainable development, engineers must become comfortable with uncertainty, interdisciplinarity, and competing perspectives. As it happens, these same attitudes and skills are components of engaged modern citizenship. 
Writing in the Chronicle of Higher Education, Michael Smith, Rebecca Nowacek, and Jeffrey Bernstein remind readers that academics in all disciplines share the responsibility of developing citizenship skills [7]. They revisit the argument first advanced in their 2010 text, Citizenship Across the Curriculum, that complex problems, such as climate change, require participation at technical and civic levels from people who possess scientific expertise, writing, “...we also believe that citizenship education embodies more abstract qualities: learning how to become more comfortable with ambiguity and complexity, how to disagree without being disagreeable, and, perhaps above all else, how to be more empathetic" [7]. Citizenship education, they say, requires, “.... breadth of knowledge from across a range of disciplines, empathy, and political participation" [7].

Noting that many disciplines assert discrete models of the natural world and interactions within it, sustainability education demands that educators work against the tendency to "isolate knowledge and different ways of knowing" [7].

\section{THE CURRICULUM}

The curriculum in MINE 422 promotes development of a sustainability mindset, and challenges students to appreciate the intersections of social and technical factors in policy decisions, and both the practical and ethical imperatives of acknowledging diverse perspectives in the design of potential solutions. The curriculum exposes students to different cultural values, particularly those of Indigenous peoples, who are disproportionately affected by mining projects. It includes a study of Canadian law (e.g., the division of powers and jurisdiction, significant cases in Aboriginal law since 1982's repatriation of the Constitution), policy and sustainability standards and reporting metrics, international human rights law and the drivers of conflict. These topics are considered via an examination of "the public" and its shifting attitudes and expectations around risk, beginning with the post -World War II enthusiasm for novel, large scale technologies, and the factors that saw trust erode: replaced first by doubt and then by distrust, after the publication of Silent Spring and a series of industrial events, the impacts of which extended into the broad community. The effects of new communication technologies and rapid news cycle on public trust in governments and technocrats as well as an increasing public expectation that they be involved in decisions, is considered as a factor in the rise of "corporate social responsibility"[8]. This survey of changing public perceptions of and tolerance for risk normalizes demands for evolving standards of practice, and prepares students to anticipate changing expectations. It fulfils the requirement to "understand relationships among technology and the social, cultural, economic and environmental conditions of society” [1].
A signature component of the course is Indigenous Cultural Safety training - an introduction the history of colonization, its reverberating impacts, and relevance for understanding the meaning and content of responsible practice. This interactive training is delivered by a skilled and sensitive educator from the university's Four Directions Indigenous Student Centre. This aspect of the course fulfils the requirement that graduates, "Act ethically and demonstrate individual accountability" [1].

\section{LEARNING ACTIVITIES}

Assignments are designed to develop skills of research, reading critically, and synthesis. In 2019, a field trip to the Canadian Institute for Mining, Metallurgy and Petroleum (CIM) symposium and networking event in Toronto allowed students to participate in policy discussions as future professionals, fulfilling learning outcomes: "Describe engineering roles in a broader context (pertaining to the environment, health, safety and public welfare)" [1], and "Recognize the impact of engineering within global society (the broader public interest)"[1] That students behaved "in a professional manner"[1], was remarked upon by industry attendees and event organizers, who later provided funding to support attendance at event in early 2020. With the pandemic restrictions of 2020, industry speakers supported the learning objectives, participating in webinars that kept enthusiastic students connected past the normal class time.

The final exam asked students to extend their learning, and to reflect on what had been learned and what was most meaningful to them.

\subsection{Engineers as Citizens}

Canada’ 2019 federal election provided an opportunity to revise the curriculum to include opportunities for students to develop insight into the relationship between public discourse, public policy and industry regulation. Following lessons in which Canada's Constitutional division of powers were covered, students worked in (lively) groups to identify five sustainability/sustainable development policy issues that fall under federal jurisdiction. They then examined the platforms (looking at websites, news reports and public statements) of the four major political parties running in the Kingston and the Islands federal riding. Working in an extended class and tutorial period, students produced a summary and critical analysis of the issues that are likely to shape the regulatory landscape of their work as graduates. They also developed advice to fellow students on where and when they could vote. Importantly, they determined both the relevant questions and the criteria for recommendation working together with only minimal guidance from the instructor. The learning outcomes for the exercise included awareness of the election, the parties and their positions, and of polling places on campus. 
Assessment considered the relevance of questions to jurisdiction and sustainable development, as well as the completeness of their research. A week after the election, an informal show of hands indicated that two thirds of the class had voted, exceeding the national average for their age group by 10 percent [9].

\subsection{Engineers as Advocates for Sustainable Practice}

Students complete certification in the Mining Association of Canada's Towards Sustainable Mining (TSM) industry recognized sustainability reporting system, demonstrating “...awareness of legal issues relevant to an engineering activity" [1] and to "identify and choose alternative ways to mitigate or prevent adverse social, environmental, health and safety impacts" [1]. They complete a detailed assignment that requires them to examine the annual sustainability report for a major Canadian miner and to work backwards by locating textual evidence that TSM and other sustainability indicators have been met. To promote literacy and a critical perspective, students must also scan three years of coverage of the company in legitimate news media (cbc.ca, The Globe and Mail, The Financial Post, The Guardian, and The New York Times) to ascertain whether the company narrative is consistent with the experience reported by affected communities and stakeholders. Depending on their findings, they must make recommendations for improving sustainability practices in the short and long term.

\subsection{Engineers as Thought-Leaders}

Because of the complexity of sustainable development, communication skills are needed, first, to build common understanding of issues, through dialogue, and second, to develop consensus around incomplete and imperfect decisions.

A lesson on dialogue and perspectives was given the week that the 2019 class began, as the student newspaper published its Climate Issue [10], with articles decrying the university's continued engagement with, and acceptance of, financial contributions from alumni working in Canada's energy sector. Colourful graphs supplemented detailed text to show the amount of research funding granted by various fossil fuel companies. Neither the graphs, nor the text revealed the aims of supported research, or how this funding compares with overall funding from all sources. Within the class, there was broad agreement that the world must transition from fossil fuels, but students are acutely aware that funding from fossil fuel industries supports research that is intended to reduce impacts during the transition. They were not happy to read the paper copies of the article distributed. They were given the task of writing an opinion piece in response, with assessment criteria of respectful acknowledgement of the original author's position, willingness to offer an alternative perspective, and logical argument and persuasiveness. Students regularly report that they are frustrated by misperceptions of what mining engineers do and how they are perceived by students in other faculties. This exercise pushed them to articulate their understanding of the dimensions of sustainability as well as their understanding of the factors that constrain solutions. Most importantly, they had to acknowledge perspectives that differed form their own and to respectfully and materially address these concerns. No student actually submitted their opinion for publication, but the work submitted for assessment showed a developing ability to step back from dismissing the views they found "uniformed" and instead, to engage in dialogue, offering the knowledge that they have had the privilege to gain, while acknowledging the sincerity of opposing views.

\section{FINAL EXAM}

The 2019 final exam in MINE nnn included a mix of questions about mining law and the division of power, Indigenous rights under S. 35 of Charter of Rights and Freedoms, the application of TSM and other sustainability reporting frameworks. One question asked them to describe how they could employ the International Association for Public Participation' spectrum of engagement. Two essay questions allowed students to apply what they had learned to a policy questions and to reflect upon how they would apply the lessons of MINE $\mathrm{nnn}$ to their future practice as professional engineers.

The first question required students to recognize and examine an "ethical and equity-based dilemma" [1] asking them to discuss the reasons why it is challenging for Canada to enact strong climate change policy. Answers to this question were consistently thoughtful and integrative. Many students were able to integrate jurisdictional competition, the impact of distinct economic structures in each Province, uncertainty around the failure to resolve land claims, social and cultural factors in risk perception as well as the political calculation of decision makers. Importantly, all answers demonstrated an awareness that societal perception is a critical consideration in implementing public policy.

The final question asked to student to reflect: to consider what they would take away and use in their future role as responsible mining engineers. For an instructor, many of the responses were moving, because they were, indeed, personal and thoughtful.

An excerpt from one exam exemplifies the responses:

"I will take sustainability and social responsibility with me as a core value wherever I go but I will more importantly try to remind myself of these questions:

- Is my decision the only option? What are the other options?

- How does this project affect the communities involved? 
- Can I see and understand other perspectives, clearly?

We need not be persuaded by the perspectives of others, of course, but our ability to realize what they are thinking and feeling makes us better citizens.”

\section{IMPACT AND LESSONS LEARNED}

After the final exam, four different students visited the instructor's office to say that they had "enjoyed the exam." This is obviously a comment no instructor expects and asking why, students said they appreciated the opportunity to reflect on their learning in the course but also to contextualize the sum of their training as engineers as they approach graduation and a career. That they remarked so strongly on this, suggests that increasing the opportunity to consider meaning not just skill and knowledge, must be a priority in future years. Research is needed to identify the value that this course is providing for students beyond attainment of listed learning outcomes. A hypothesis is that as students perceive increasing uncertainty and complexity, reflection and citizenship skills may provide a sense of agency, a sense that they can use their engineering skills to make a difference. This research has yet to be undertaken.

\section{2020 REALIZING OPPORTUNITIES IN A PANDEMIC}

The pandemic iteration of the course became a blend of online synchronous and asynchronous learning. Some plans for curriculum development were subordinated to a focus on student well-being, but small opportunities to curate current media content for inclusion were seized. CBC News video, academic blogs and radio podcasts were added to bring a variety of voices about land, about cultural justice, and about opportunities to envision that mining as vehicle for the development of resilient and sustainable communities to the virtual classroom.

All assignments and activities were designed to illuminate diverse perspectives, and to explore sources of difference and ways to collaborate or reach consensus. Opportunities to reflect were provided and an accepting classroom made reflection safe.

Before classes began, students were sent a video welcome from the instructor. They were asked to make their own short introductory video. They were to describe a place that was important to them-a place where they had formed good memories, their home, or a place where they felt peaceful. This activity seeded the concept of land as deep and definitional part of our being. An expanded Indigenous component of the course built on the notion of land as contributing to identity and spirituality, as students learned from Indigenous scholars, including Hayden King, why Land Acknowledgements are inadequate, and what is required in a respectful acknowledgement. Students reported finding this lesson to be "eye-opening" and meaningful, as they learned about the peoples of their special place and reflected upon their own relationship to and responsibilities to the land and people, and how this carries into the lands where they will one day work.

Acknowledging that graduates will be on a path to industry leadership, the first assignment, a journal paper review, was replaced with a comparative review of two papers on the concept of "Shared Value," strengthening the conceptual link between sustainability and business strategy.

As in previous years, students completed the Mining Association of Canada's Towards Sustainable Mining certification, a program of online training that introduces the standards and indicators used by Canadian companies to report on their performance. Two assignments reinforce the learning and being able to obtain an industry certification ensures that students link the course to their career aspirations.

2020 featured a more substantial treatment of major reporting standards, which are of increased important to industry and communities alike. Specialists from Deloitte and Touche's Sustainability Group conducted a live webinar discussing the future of sustainability reporting and the forces driving shifts in focus. As the new Global Reporting Initiative (GRI) standards and the Sustainability Accounting Standards Board (SASB) standards become more widely applied and as mining engineering schools increase their emphasis on business and management, the growing dependence of mine finance and sustainable practice is clear. Social and environmental responsibility is no longer an after-thought-it is fundamental to practice. Guest speaker Monica Ospina [11] spoke about everpresent opportunities for mining engineers to contribute to social development. Students reported that this two-hour interactive talk was inspiring and made them feel positive about their career choice at a time of great uncertainty.

\section{THE FUTURE}

Addressing climate change and Reconcilation [13] are the most important projects for citizens of Canada. Mining engineers will be play a pivotal role in ensuring that both goals can be met.

An expanded emphasis on the development of Intercultural Competence is planned for 2021, and, if face-to-face learning resumes, an additional week that familiarizes students with Indigenous worldviews will delivered through land-based learning [13]. An emphasis on landbased learning poses logistical challenges but will be pursued with the goal of helping to fulfil the University's commitment to decolonizing the curriculum. With so many mines located on the traditional territories of Indigenous Canadians, the citizen engineer, has a unique role to play in reconciliation. 


\section{Acknowledgements}

Laura Maracle, a proud Mohawk woman is an educator from Queens University's Four Directions Indigenous Student Centre. She has shared a priceless gift with all of us in MINE 422 through the emotional work of conducting the KAIROS Blanket Exercise. Laura's warmth and generosity of spirit is a profound inspiration. I am so very grateful for her commitment to this project. I am grateful also to Mark Mellen and Stephanie Sterk of Deloitte and Touche's Sustainability \& KPI Services Group. The Canadian Institute for Mining, Metallurgy and Petroleum (CIM) provided support for Monica Ospina's talk through their Distinguished Lecturer program. Finally, to the classes of 2020 and 2021, it has been my very great pleasure and honour to accompany you along the road to practice as responsible mining and geological engineers.

\section{References}

[1] Renee Heath. "Rethinking Community collaboration through a dialogic lens: creativity, democracy, and diversity in community organizing," Management Communication Quarterly, vol. 21 no. 2 pp. 145-171, 2007. Available as of May 1, 2021, from http://mcq.sagepub.com/cgi/content/abstract/21/2/145

[2] Engineers Canada, Graduate Attributes. Available as of February $1, \quad 2020$ from https://engineerscanada.ca/sites/default/files/GraduateAttributes.pdf

[3] Susan Toohey, Designing Courses for Higher Education. Buckingham, UK: The Society for Research into Higher Education \& the Open University Press, 1999, 217 pp.

[4] Etienne Wenger, Communities of practice: Learning, meaning, and identity. Cambridge: Cambridge University Press, 1998, 318 pp.
[5] Samuel Florman, The Existential Pleasures of Engineering, London: St. Martin's Press, 1996, 224 pp.

[6] Oxford University Press, 1987, pp. 383. Available as of February 1, 2020 from https://sustainabledevelopment.un.org/content/documents/5 987our-common-future.pdf

[7] Michael Smith, Rebecca Nowacek, and Jeffrey Bernstein, “Don't retreat. Teach citizenship,” The Chronicle of Higher Education, January 19, 2017. Available as of February 1, 2020 from https://www.chronicle.com/article/Don-tRetreat-Teach/238923

[8] D. Whetten, G. Rands, and P. Godfrey, P. "What are the responsibilities of business to society?” In A. Pettigrew, $\mathrm{H}$. Thomas, and R. Whittington (Eds.), Handbook of Strategy and Management, London: Sage, 2002, p 373-408.

[9] Elections Canada, "Voter turnout by sex and age," August 6, 2020. Available as of December 28, 2020 at https://www.elections.ca/content.aspx?section=res\&dir=rec leval/pes2019/vtsa\&document=index\&lang=e

[10] Queen’s Journal, The Climate Issue, September 13, 2019. Kingston: Queen's University Alma Mater Society.

[11] Monica Ospina, CIM Distinguished Lecturer 2020-21. Available as of January 4, 2021 at https://www.cim.org/awards/cim-distinguished-lecturers/

[12] Mining Association of Canada. Towards Sustainable Mining. Available as of April 15, 2021 at https://mining.ca/towards-sustainable-mining/

[13] Kate McCoy, Eve Tuck and Marcia McKenzie, Land Education: Rethinking Pedagogies of Place from Indigenous, Postcolonial, and Decolonizing Perspectives. London: Taylor and Francis, 2016, 152 pp. 